\title{
Co-existent Epicardial Paraganglioma and Anterior Mediastinal Thymoma
}

\author{
Matthew G Dudgeon ${ }^{1 *}$, Sushilkumar K Sonavane ${ }^{2}$, Ephraim E Parent ${ }^{3}$, Andras Khoor ${ }^{4}$, \\ Mathew Thomas ${ }^{5}$ \\ 1. Department of Radiology, Mayo Clinic, Jacksonville, FL, USA \\ 2. Department of Radiology, Division of Cardiothoracic Imaging, Mayo Clinic, Jacksonville, FL, USA \\ 3. Department of Radiology, Division of Nuclear Medicine, Mayo Clinic, Jacksonville, FL, USA \\ 4. Department of Laboratory Medicine and Pathology, Mayo Clinic, Jacksonville, FL, USA \\ 5. Department of Cardiovascular/Thoracic Surgery, Mayo Clinic, Jacksonville, FL, USA
}

* Correspondence: Matthew G. Dudgeon, 4500 San Pablo Road South, Jacksonville, FL 32224, USA

(\Dudgeon.Matthew@mayo.edu)

Radiology Case. 2020 Oct; 14(10):16-30 :: $\quad$ DOI: 10.3941/jrcr.v14i10.4101

\begin{abstract}
Thymoma and paraganglioma are known causes of mediastinal masses, the latter being extremely rare. Thymomas arise from remnant thymic tissue in the anterior mediastinum; whereas, thoracic paragangliomas arise from paraaortic or para-vertebral sympathetic chain ganglion (derivatives of embryonic neural crest) in the middle or posterior mediastinum. We report a case of a middle-aged woman with two mediastinal masses, originally believed to be a single tumor or primary malignancy with adjacent metastasis on Computed Tomography (CT) that were further delineated with Magnetic Resonance Imaging (MRI) and [68Ga]-DOTA-(Tyr3)-octreotate (DOTA-TATE) Positron Emission Tomography-Computed Tomography (PET-CT) and surgical pathology as two distinct entities: left epicardial paraganglioma and anterior mediastinal thymoma. A comprehensive discussion of both entities is included.
\end{abstract}

\section{CASE REPORT}

\section{CASE REPORT}

A 58-year-old woman presented to an outside hospital via emergency medical services for crushing chest pain and was found to have one millimeter ST-segment elevation in leads II, III, AVF and V5-V6.

She was taken for emergent cardiac catheterization with the working diagnosis of inferior wall myocardial infarction. During cardiac catheterization, no evidence of coronary artery disease was found. However, a large, highly vascularized mass along the anterior basal wall of the left ventricle was observed under fluoroscopy. Blood supply to the mass was seen originating from both coronary arteries, but predominantly from the left anterior descending coronary artery (Figure 1a, 1b).

Computed Tomography Angiogram (CTA) of the Chest was then obtained for better anatomical delineation of the mass. CTA revealed a large mass within the pericardium that was located along the anterior left atrioventricular groove extending superiorly up to the level of pulmonary trunk and 
showed marked contrast enhancement (Figure 2a, 2b). Dilated arterial branches from the left coronary artery and dilated, tortuous venous branches draining in the coronary sinus were noted (Figure 2c). Superiorly within the anterior mediastinum, another lobulated component/mass with mild contrast enhancement was seen in front of the great vessels (Figure 3a, $3 \mathrm{~b})$. The pericardial mass was thought to be contiguous with the anterior mediastinal mass and a differential of local pericardial extension or metastasis of the anterior mediastinal mass was suggested. Moderate size pericardial and small bilateral pleural effusions were also present (Figure 2). Transthoracic echocardiogram was subsequently performed showing a large, echogenic, and vascular mass anterior to the left ventricle, with the additional finding of a moderate to large circumferential pericardial effusion causing early cardiac tamponade physiology (Figure 4). An emergent pericardial window was performed with symptomatic relief of chest pain. The patient was subsequently transferred to our institution for further management with CTA images.

After arrival, the patient underwent CT-guided biopsy of the superiorly located, mildly enhancing anterior mediastinal soft tissue mass. Pathologic analysis of the obtained tissue was consistent with thymoma (type AB) that is discussed with images later under pathology section.

After multidisciplinary consultation, MRI of the Chest without and with intravenous contrast was performed to better assess the extent of the mass for local spread as pericardial extension or metastasis of thymoma are less common. MRI of the Chest showed a well-defined $6.2 \times 5.8 \times 4.6 \mathrm{~cm}$, lobulated, low to intermediate $\mathrm{T} 1$ and mildly increased $\mathrm{T} 2$ signal intensity (SI) lesion in the anterior mediastinum with mild homogenous contrast enhancement, consistent with an appearance of thymoma (Figure 5). Another, inferiorly located, $7.0 \times 6.7 \times 6.5 \mathrm{~cm}$, low T1, markedly increased T2 SI, lobulated lesion with intense homogenous contrast enhancement within left epicardial space (Figure 6) was seen with a distinct plane between the two masses separated by parietal pericardium (Figure 7). The epicardial lesion was causing mass effect on the lateral wall of the left ventricle and involvement of the underlying myocardium was difficult to exclude (Figure 7). The location and imaging characteristics of the epicardial mass suggested the possibilities of paraganglioma, hemangioma or sarcoma, rather than extension or metastasis of a thymoma. Additional mildly enlarged mediastinal lymph nodes were present. The largest measured up to $2.1 \mathrm{~cm}$ in short axis and was located at the aortopulmonary window level (Figure 5).

Given the degree of vascularity and epicardial location of the inferior mass, percutaneous CT guided biopsy request was denied. After consultation with Nuclear Medicine, the patient underwent DOTA-TATE PET-CT as paraganglioma was favored amongst the differentials. The left epicardial mass was intensely DOTA-TATE avid with maximum standardized uptake value (max SUV) of 68.7 (Figure 8). This appearance was felt to be most consistent with a well-differentiated neuroendocrine tumor or paraganglioma. In contrast, the anterior mediastinal mass showed only minimal Ga-68 DOTA-TATE avidity (max SUV 2.5) (Figure 8) and was consistent with biopsy proven thymoma. No additional areas of DOTA-TATE uptake were noted on the scan to suggest metastatic disease.

The patient underwent outpatient consultation with Cardiothoracic Surgery for pre-surgical planning. During consultation, a family history of pericardial masses was obtained. Patient's biologic sister as well as two twin maternal aunts each had a surgical history of cardiac / pericardial mass removal that were pathologically confirmed paragangliomas. Genetic testing revealed a heterozygous alteration in the succinate dehydrogenase complex iron sulfur subunit $\mathrm{B}$ (SDHB) gene. The SDHB protein plays a critical role in the mitochondria. A mutation in the SDHB gene is one known cause of familial paragangliomas $[1,2]$.

Surgery: The patient underwent simultaneous resection of both masses (Figure 9) through a median sternotomy. During resection of the epicardial mass under cardiopulmonary bypass, the left main coronary artery was observed to be supplying the mass and was sacrificed. A left internal mammary artery to left anterior descending artery bypass was performed. Her postoperative course was complicated by left heart failure and she eventually underwent orthotopic heart transplant 3 months later. She was discharged home 9 days after her transplant.

Pathology: The surgery resulted in five specimens: a $9 \mathrm{~cm}$ anterior mediastinal mass, a $6.5 \mathrm{~cm}$ epicardial mass, and three lymph node biopsies. Histologically, the anterior mediastinal mass was well demarcated and showed a lobulated architecture (Figure 10a). At higher magnification, it exhibited characteristic features of a type $A B$ thymoma with both lymphocyte-poor type A and lymphocyte-rich type B elements (Figure 10b). The epicardial mass was a typical paraganglioma. The bland, round or oval synaptophysinpositive tumor cells were arranged in small well-formed nests (Zellballen), which were surrounded by S-100-positive sustentacular cells (Figure 11). The right paratracheal, right anterior mediastinal and aortopulmonary window lymph nodes were negative for neoplasm.

\section{DISCUSSION}

\section{Paraganglioma}

Etiology and Demographics:

Paragangliomas are rare neuroendocrine tumors arising from the extra-adrenal sympathetic or parasympathetic autonomic paraganglia (derivatives of embryonic neural crest) with approximately $1-2 \%$ percent arising in the thorax [3]. Paragangliomas are very similar to pheochromocytomas and World Health Organization Classification refers to pheochromocytomas as intra-adrenal paragangliomas [4,5]. However, the distinction between the two is important as pheochromocytoma has a higher risk for metastasis [6]. The incidence of combined paraganglioma/pheochromocytoma is approximately 0.8 per 100,000 person years with around 500 to 1600 cases annually in the United States [7]. Paragangliomas are often diagnosed between ages of 30 to 50 years. Most paragangliomas are sporadic and seen much more 
commonly in women. Hereditary paragangliomas make up one third to one half of diagnosed paragangliomas and show an equal distribution between men and women [8]. Mutations in the succinate dehydrogenase complex (SDH) have been linked to hereditary paraganglioma/pheochromocytoma [1]. The SDH mitochondrial enzyme is an attachment site for electrons as they are transferred through the oxidative phosphorylation pathway [1]. The SDH mitochondrial enzyme has four subunits (A, B, C, D) encoded by the four nuclear genes: SDHA, SDHB, SDHC, and SDHD, with an additional fifth SDHAF2 subunit that is required for flavination of the SDHA subunit. Five hereditary paraganglioma syndromes have been described, corresponding to mutations in each of the five subunits [1]. Paraganglioma syndrome 4 (PGL4) is associated with mutations in SDHB and is the most common of the five (PGL1-PGL5) and what our patient was diagnosed with [1]. Other hereditary syndromes associated with paragangliomas include: Multiple Endocrine Neoplasia (MEN) 2 (Medullary thyroid cancer, parathyroid tumors), Neurofibromatosis 1 (café-au-lait spots, neurofibromas), Von Hippel-Lindau (central nervous system and retinal hemangioblastomas, renal cell carcinoma, endolymphatic sac tumors), Carney-Stratakis syndrome (gastrointestinal stromal tumor) [1].

\section{Clinical \& Imaging Findings:}

Thoracic paragangliomas arise from para-aortic or paravertebral sympathetic chain ganglion in the middle or posterior mediastinum. Pericardial paragangliomas are even rarer and can be seen along the roof of left atrium, interatrial septum, and free wall of the right atrium [3]. Our case shows an unusual location of paraganglioma: along the anterior wall of the left ventricle in the epicardial space. These are highly vascular tumors and derive their blood supply from adjacent coronary arteries, as seen in our case.

The vast majority of paragangliomas are nonfunctional (approximately 80 to 90 percent) and symptoms, if present, are a result of mass effect [4]. Acute presentation with chest pain in our case is explained by moderate to severe pericardial effusion, presumably from underlying tumor, causing cardiac tamponade physiology as pericardiocentesis resulted in symptomatic relief.

Paragangliomas have characteristic findings on imaging. On CT, they are seen as homogenous, soft tissue masses that strongly enhance with intravenous contrast. Paragangliomas are highly vascular and dilated internal vessels may be visible on CT [9]. On MRI, a soft tissue mass with relative high T1 signal intensity, flow voids may be present due to dilated vessels. They show marked T2 high signal intensity compared to liver on T2 weighted images ('light bulb sign') and marked enhancement with gadolinium [9]. Molecular imaging of paragangliomas with DOTA-TATE and [123I]metaiodobenzylguanidine (MIBG) have shown high specificity and sensitivity in identifying sites of primary disease and metastatic spread. Paragangliomas that follow the pseudohypoxic tricarboxylic acid cycle pathway, which include those with familial SDH mutations such as in this case, overexpress the somatostatin receptor, particularly the SSTR type 2 (SSTR2). DOTA-TATE targets the SSTR2 receptor with high affinity and affords a near perfect detection rate for primary and metastatic paragangliomas [10]. MIBG continues to have a role in identifying paragangliomas that follow the Kinase signaling pathway, which are found in a separate subset of genetic subtypes including MEN type 2 [11].

\section{Differential Diagnoses:}

Differential diagnoses of epicardial or pericardial enhancing masses include metastasis, primary pericardial tumors such as sarcoma, mesothelioma, veno-lymphatic malformations (hemangioma, lymphangioma), coronary artery aneurysm and arterio-venous malformation (AVM) [12]. Rarely, ectopic thyroid tissue, parathyroid adenomas have been reported in juxta cardiac location [13.14].

\section{Metastasis}

Metastases are estimated to be 20-40 times more common than primary cardiac tumors [15]. Pericardial involvement is the most common cardiac site of metastasis followed by the epicardium and myocardium [16]. Metastases can have a varied imaging appearance such as nodule/ mass, multilobulated/irregular margins, variable degree of enhancement/necrosis based upon the primary site, aggressiveness of malignancy. Often, there is associated pericardial effusion and/or thickening. The common primary malignancies with metastasis to heart and pericardium are lung, breast, lymphoma, melanoma, renal cell carcinoma [17]. Pericardial metastases are seen late in the course of malignancy or as a part of recurrence, thus a history of known underlying malignancy is the key.

\section{Primary pericardial malignancy}

Cardiac tumors are rare with primary pericardial tumors being even rarer, comprising only approximately $6.7 \%-12.8 \%$ of all primary cardiac tumors [18,19]. Malignant involvement of the pericardium by direct invasion or metastatic disease is 100-1000 times more prevalent than primary pericardial malignancy [20,21]. Primary malignant tumors of the pericardium include sarcoma, mesothelioma, and lymphoma [22]. In comparison with pericardial paraganglioma, primary pericardial malignancy on imaging shows infiltrative nature, marked internal heterogeneity, mild to moderate contrast enhancement, restricted diffusion on MRI imaging and the presence of aggressive loco regional invasion and metastasis.

\section{Veno-lymphatic malformation}

Veno-lymphatic malformations are a varied group of lesions that include, among others, hemangioma and lymphangioma. Specifically, hemangiomas are benign tumors of blood vessels with dilated, thin walled vascular spaces. Pericardial hemangiomas are exceedingly rare with fewer than 200 case reports in the literature [12]. Similar to paragangliomas, they typically show rapid enhancement on CT imaging. However on MRI, hemangiomas often demonstrate intermediate T1-weighted signal intensity and high T2-weighted signal intensity compared to muscle. Perfusion is often heterogeneous with enhancement on delayed post contrast imaging [12]. Lymphangioma comprise of lymph containing, endothelial lined thin walled spaces that are separated from the lymphatic system. These are variable sized multiloculated lesions with thin internal septations [23]. 


\section{Coronary artery malformations (AVM, fistula)}

Coronary artery malformations are a diverse group of both congenital and acquired anatomical abnormalities. While imaging appearances can be varied, the malformation should be in direct communication with one or more coronary vessels. The affected vessels are dilated and tortuous and MRI signal follows blood signal intensity on non-contrast and post contrast images, in comparison to paraganglioma.

\section{Ectopic thyroid and parathyroid tissue}

Ectopic thyroid and parathyroid tissue is most often found in the neck, often somewhere between the tongue base and thyroid bed, along the path of developmental descent. Rarely, ectopic thyroid or parathyroid tissue has been reported in the chest, typically in the anterior or middle mediastinum. Very rarely, juxta cardiac locations are also reported [13,14]. CT scans often show well defined, soft tissue nodule or mass of variable size with avid contrast enhancement, maintaining fat planes with adjacent viscera. MRI often shows T1 iso to mild high signal intensity and T2 mild high signal intensity compared to skeletal muscles. Radionuclide studies with iodine for thyroid and sestamibi for parathyroid are excellent for visualization of ectopic tissue [13].

\section{Treatment \& Prognosis:}

For paragangliomas without local spread /invasion, surgical excision remains the standard of care [24]. The majority of paragangliomas are benign with approximately 15$35 \%$ displaying malignant behavior [24].

\section{Thymoma}

\section{Etiology \& Demographics:}

Thymoma and thymic carcinoma are often grouped together under the umbrella of thymic epithelial tumors. Thymic epithelial tumors are rare with an incidence of approximately 0.13 cases per 100,000 person years [25,26]. Thymoma is the most common tumor of the anterior mediastinum, often occurring between ages of 40-60 years with an equal predilection for men and women [27, 28].

\section{Clinical \& Imaging Findings:}

Thymoma typically presents clinically in one of three ways: incidental finding on imaging, thoracic symptoms secondary to mass effect (including chest pain) or as a result of a paraneoplastic syndrome. Many paraneoplastic syndromes have been associated with thymoma (more than thymic carcinoma), the most common being myasthenia gravis [29]. Up to one half of patients with thymoma have symptoms consistent with myasthenia gravis [29]. However, only ten percent of patients with diagnosed myasthenia gravis have a thymoma [30]. Myasthenia gravis is rarely seen with thymic carcinoma [30].

On CT, thymoma is seen as rounded or lobulated, homogenous, soft tissue mass in the anterior mediastinum anywhere from suprasternal notch up to the diaphragm [31]. Drop metastases to the pleura are known to show similar imaging and contrast features [31]. On MR, it shows iso-low $\mathrm{T} 1$, intermediate $\mathrm{T} 2$ signal intensity with variable, typically mild, contrast enhancement [32]. Areas of cavitation or calcifications are rare in low grade thymoma [30]. Worrisome features on imaging such as heterogeneity, calcification, low density areas (hemorrhage, necrosis or cystic change), obscuration of surrounding fat planes and invasion/metastasis are concerning for high grade thymoma or thymic carcinoma [30]. [18F] 2-fluoro 2-deoxy-D glucose (FDG) PET-CT helps to distinguish between low risk thymoma and high risk thymoma/thymic carcinoma [30]. In the present case, the location and MR characteristics are typical for a thymoma.

\section{Differential Diagnoses:}

Differential diagnoses for anterior mediastinal masses apart from thymic tumors include lymphadenopathy such as from lymphoma, metastasis, germ cell tumor, and retrosternal extension of thyroid mass.

\section{Lymphadenopathy}

Lymphadenopathy secondary to wide spectrum of malignant and nonmalignant etiologies is a common cause of anterior mediastinal masses. Lymphoma accounts for approximately $20 \%$ of mediastinal neoplasms in adults [33]. Lymphadenopathy and thymoma can potentially have many overlapping imaging characteristics across modalities such as well-defined rounded or lobulated soft tissue mass with variable contrast enhancement. Multifocal areas of involvement favor lymphadenopathy over thymoma for an anterior mediastinal mass.

\section{Thyroid masses with mediastinal extension}

Thyroid goiter causes enlargement of thyroid gland, often with multiple nodules and calcification is present in approximately $75 \%$ of cases [34]. Thyroid malignancy is another cause for thyroid gland enlargement. Moderate to severe enlargement of thyroid leads to downward extension, often in the anterior or middle mediastinum. A thyroid mass should be seen in continuity with the normal thyroid gland. In contrast, a normal appearing native thyroid gland is often seen separate in patients with a thymoma [31].

\section{Germ cell tumor}

Germ cell tumors are a heterogeneous group of malignancies originating from primitive germ cell layers (ectoderm, mesoderm and endoderm) [33]. Outside the gonads, the anterior mediastinum is the most common location for germ cell tumors [33]. Teratoma is one type of germ cell tumor that can be found in the anterior mediastinum and contain derivatives from any of the three germ cell layers. The presence of macroscopic fat within an anterior mediastinal mass is nearly pathognomic for teratoma and would not be expected in a thymoma [33]. Cystic areas and calcifications are often seen in teratoma but are extremely rare in low grade thymoma [30,33].

\section{Treatment \& Prognosis:}

Thymoma and thymic carcinoma are a spectrum of disease and where a patient falls on the spectrum implies great variation in treatment and prognosis $[35,36,37]$. If the patient is a surgical candidate, thymectomy is the current standard of care. Histologic grading of thymoma includes: A, AB, B1, B2 and B3 (from the lowest to the highest grade). For the 
histological subtype that our patient had (type AB), five year survival ranges from $87-100 \%$, compared to $36 \%$ for inoperable, locally advanced thymic carcinoma. Chance of local recurrence is lower in patients with thymoma compared with thymic carcinoma [35,36,37].

There are two case reports in the literature describing concomitant head and neck paraganglioma and thymoma [38, 39]. To our knowledge, this is the first case description of paraganglioma in the epicardial space and thymoma. Coexistence of paraganglioma and thymic malignancy is extremely rare and can be sporadic. However, the previous reports, proposed a possibility from common neuroectodermal origin. Neuroectodermal elements within thymus could be part of paraganglionic rests or misplaced embryonal structures within mediastinum [38, 39]. The most common neuroendocrine tumor in the anterior mediastinum arises from thymus: thymic carcinoid [35]. However, the thymic masses in previous two reports and our case were thymoma and not thymic carcinoid.

Interestingly, malignant potential is most common in hereditary paragangliomas associated with the SDHB mutation and Paraganglioma Syndrome 4 (PGL4), as in our patient [24]. However, post-surgery pathologic analysis in this case showed no detectable loco regional spread. Hereditary paraganglioma syndrome is inherited in an autosomal dominant pattern and familial screening can be performed for hereditary paraganglioma syndromes with head, neck, spine MR without contrast [40].

Conclusion: After an extensive literature search, this appears to be the first case report of a patient with hereditary paraganglioma syndrome presenting with co-existent epicardial paraganglioma and thymoma. Imaging played a crucial role in the diagnosis and management, as both the tumors have distinct imaging characteristics.

\section{TEACHING POINT}

Paraganglioma and thymoma are known causes of mediastinal masses but their co-existence is extremely rare. Multidisciplinary management including genetic analysis and genetic counselling is important as some of the paragangliomas have syndromic association.

\section{REFERENCES}

1. Opocher G, Schiavi F. Genetics of pheochromocytomas and paragangliomas. Best Pract Res Clin Endocrinol Metab. 2010 Dec;24(6):943-56. PubMed PMID: 21115163.

2. Astuti D, Latif F, Dallol A, Dahia PL, Douglas F, George E, Sköldberg F, Husebye ES, Eng C, Maher ER. Gene mutations in the succinate dehydrogenase subunit SDHB cause susceptibility to familial pheochromocytoma and to familial paraganglioma. Am J Hum Genet. 2001 Jul;69(1):49-54. PubMed PMID: 11404820.
3. Ramlawi B, David EA, Kim MP, Garcia-Morales LJ, Blackmon SH, Rice DC, Vaporciyan AA, Reardon MJ. Contemporary surgical management of cardiac paragangliomas. Ann Thorac Surg. 2012 Jun;93(6):1972-6. PubMed PMID:22537533.

4. Young WF Jr. Paragangliomas: clinical overview. Ann N Y Acad Sci. 2006 Aug;1073:21-9. PubMed PMID: 17102068.

5. Tischler AS, Kimura N, Mcnicol AM. Pathology of pheochromocytoma and extra-adrenal paraganglioma. Ann N Y Acad Sci. 2006 Aug;1073:557-70. PubMed PMID: 17102124.

6. Pacak K, Eisenhofer G, Ahlman H, Bornstein SR, GimenezRoqueplo AP, Grossman AB, Kimura N, Mannelli M, McNicol AM, Tischler AS. Pheochromocytoma: recommendations for clinical practice from the First International Symposium. October 2005. Nat Clin Pract Endocrinol Metab. 2007 Feb;3(2):92-102. PubMed PMID: 17237836 .

7. Kimura N, Takekoshi K, Naruse M. Risk Stratification on Pheochromocytoma and Paraganglioma from Laboratory and Clinical Medicine. J Clin Med. 2018 Aug 27;7(9). PubMed PMID: 30150569; PubMed Central PMCID: PMC6162838.

8. Crona J, Taïeb D, Pacak K. New Perspectives on Pheochromocytoma and Paraganglioma: Toward a Molecular Classification. Endocr Rev. 2017 Dec 1;38(6):489-515. PubMed PMID: 28938417; PubMed Central PMCID: PMC5716829.

9. Withey SJ, Perrio S, Christodoulou D, Izatt L, Carroll P, Velusamy A, Obholzer R, Lewington V, Jacques AET. Imaging Features of Succinate Dehydrogenase-deficient Pheochromocytoma-Paraganglioma Syndromes. Radiographics. 2019 Sep-Oct;39(5):1393-1410. PubMed PMID: 31498738.

10. Janssen I, Chen CC, Millo CM, Ling A, Taieb D, Lin FI, Adams KT, Wolf KI, Herscovitch P, Fojo AT, Buchmann I, Kebebew E, Pacak K. PET/CT comparing (68)GaDOTATATE and other radiopharmaceuticals and in comparison with CT/MRI for the localization of sporadic metastatic pheochromocytoma and paraganglioma. Eur J Nucl Med Mol Imaging. 2016 Sep;43(10):1784-91. PubMed PMID: 26996779.

11. Crona J, Taïeb D, Pacak K. New Perspectives on Pheochromocytoma and Paraganglioma: Toward a Molecular Classification. Endocr Rev. 2017 Dec 1;38(6):489-515. Review. PubMed PMID: 28938417; PubMed Central PMCID: PMC5716829.

12. Maleszewski JJ, Anavekar NS. Neoplastic Pericardial Disease. Cardiol Clin. 2017;35(4):589-600.

13. Ahuja K, Bhandari T, Banait-Deshmane S, Crowe DR, Sonavane SK. Incidentally detected ectopic thyroid in juxta cardiac location-Imaging and pathology. Radiol Case Rep. 2018;13(4):909-913. Published 2018 Jul 9. 
14. Xin Y, Zhao T, Wei B, et al. Intrapericardial parathyroid carcinoma: a case report [published online ahead of print, 2020 Apr 4]. Endocrine. 2020;10.1007/s12020-020-02283-8.

15. Al-Mamgani A, Baartman L, Baaijens M, de Pree I, Incrocci L, Levendag PC. Cardiac metastases. Int J Clin Oncol. 2008;13(4):369-372.

16. Bussani R, De-Giorgio F, Abbate A, Silvestri F. Cardiac metastases. J Clin Pathol. 2007;60(1):27-34.

17. Chiles C, Woodard PK, Gutierrez FR, Link KM. Metastatic involvement of the heart and pericardium: CT and MR imaging. Radiographics. 2001;21(2):439-449.

18. Meng Q, Lai H, Lima J, Tong W, Qian Y, Lai S. Echocardiographic and pathologic characteristics of primary cardiac tumors: a study of 149 cases. Int J Cardiol. 2002;84(1):69-75.

19. Patel J, Sheppard MN. Pathological study of primary cardiac and pericardial tumours in a specialist UK Centre: surgical and autopsy series. Cardiovasc Pathol. 2010;19(6):343-352.

20. Grebenc ML, Rosado de Christenson ML, Burke AP, Green CE, Galvin JR. Primary cardiac and pericardial neoplasms: radiologic-pathologic correlation. Radiographics. 2000;20(4):1073-1112.

21. Restrepo CS, Vargas D, Ocazionez D, Martínez-Jiménez S, Betancourt Cuellar SL, Gutierrez FR. Primary pericardial tumors. Radiographics. 2013;33(6):1613-1630.

22. Wang ZJ, Reddy GP, Gotway MB, Yeh BM, Hetts SW, Higgins CB. CT and MR imaging of pericardial disease. Radiographics. 2003;23 Spec No:S167-S180.

23. Araoz PA, Mulvagh SL, Tazelaar HD, Julsrud PR, Breen JF. CT and MR imaging of benign primary cardiac neoplasms with echocardiographic correlation. Radiographics. 2000;20(5):1303-1319.

24. Tufton N, Sahdev A, Akker SA. Radiological Surveillance Screening in Asymptomatic Succinate Dehydrogenase Mutation Carriers. J Endocr Soc. 2017 Jul 1;1(7):897-907. PubMed PMID:29264540; PubMed Central PMCID:PMC5686572.

25. Engels EA. Epidemiology of thymoma and associated malignancies. J Thorac Oncol. 2010 Oct;5(10 Suppl 4):S2605. PMID: 20859116; PMCID: PMC2951303.

26. Duwe BV, Sterman DH, Musani AI. Tumors of the mediastinum. Chest. 2005 Oct;128(4):2893-909. PubMed PMID: 16236967.

27. Drevet G, Collaud S, Tronc F, Girard N, Maury JM. Optimal management of thymic malignancies: current perspectives. Cancer Manag Res. 2019 Jul 22;11:6803-6814. PMID: 31413632; PMCID: PMC6660626.
28. Safieddine N, Liu G, Cuningham K, Ming T, Hwang D, Brade A, Bezjak A, Fischer S, Xu W, Azad S, Cypel M, Darling G, Yasufuku K, Pierre A, de Perrot M, Waddell T, Keshavjee S. Prognostic factors for cure, recurrence and longterm survival after surgical resection of thymoma. J Thorac Oncol. 2014 Jul;9(7):1018-1022. PubMed PMID: 24926546.

29. Nishino M, Ashiku SK, Kocher ON, Thurer RL, Boiselle PM, Hatabu H. The thymus: a comprehensive review. Radiographics. 2006 Mar-Apr;26(2):335-48. PubMed PMID: 16549602

30. Di Mango AL, Zanetti G, Marchiori E. Thymoma metastasis: Differential diagnosis of pleural nodules and masses. Lung India. 2018 Jul-Aug;35(4):369-370. PubMed PMID:29970789; PubMed Central PMCID:PMC6034374.

31. Kurihara N, Saito H, Nanjo H, Konno H, Atari M, Saito Y, Fujishima S, Kameyama K, Minamiya Y. Thymic carcinoma with myasthenia gravis: Two case reports. Int J Surg Case Rep. 2016;27:110-112. Epub 2016 Aug 11. PubMed PMID: 27591911; PubMed Central PMCID: PMC5021770.

32. de Jong WK, Blaauwgeers JL, Schaapveld M, Timens W, Klinkenberg TJ, Groen HJ. Thymic epithelial tumours: a population-based study of the incidence, diagnostic procedures and therapy. Eur J Cancer. 2008 Jan;44(1):123-30. PubMed PMID: 18068351.

33. Shahrzad M, Le TS, Silva M, Bankier AA, Eisenberg RL. Anterior mediastinal masses. AJR Am J Roentgenol. 2014;203(2):W128-W138.

34. Gaitan E, Nelson NC, Poole GV. Endemic goiter and endemic thyroid disorders. World J Surg. 1991;15(2):205-215.

35. Rena O, Papalia E, Maggi G, Oliaro A, Ruffini E, Filosso P, Mancuso M, Novero D, Casadio C. World Health Organization histologic classification: an independent prognostic factor in resected thymomas. Lung Cancer. 2005 Oct;50(1):59-66. PubMed PMID: 16009453.

36. Kondo K, Yoshizawa K, Tsuyuguchi M, Kimura S, Sumitomo M, Morita J, Miyoshi T, Sakiyama S, Mukai K, Monden Y. WHO histologic classification is a prognostic indicator in thymoma. Ann Thorac Surg. 2004 Apr;77(4):1183-8. PubMed PMID: 15063231.

37. Ogawa K, Toita $\mathrm{T}$, Uno $\mathrm{T}$, Fuwa N, Kakinohana $\mathrm{Y}$, Kamata M, Koja K, Kinjo T, Adachi G, Murayama S. Treatment and prognosis of thymic carcinoma: a retrospective analysis of 40 cases. Cancer. 2002 Jun 15;94(12):3115-9. PubMed PMID: 12115342.

38. Refior M, Mees K. [Coexistence of bilateral paraganglioma of the A. carotis, thymoma and thyroid adenoma: a chance finding?]. Laryngorhinootologie. 2000 Jun;79(6):337-40. PubMed PMID: 10923313.

39. Bano G, Sennik D, Kenchaiah M, Kyaw Y, Snape K, Tripathi V, Wilson P, Vlahos I, Hunt I, Hodgson S. A case of co-existing paraganglioma and thymoma. Springerplus. 
2015;4:632. PubMed PMID: 26543766; PubMed Central PMCID: PMC4628025.

40. Millar S, Bradley L, Donnelly DE, Carson D, Morrison PJ. Familial pediatric endocrine tumors. Oncologist. 2011;16(10):1388-96. PMID: 21934104; PMCID: PMC3228066.

\section{FIGURES}

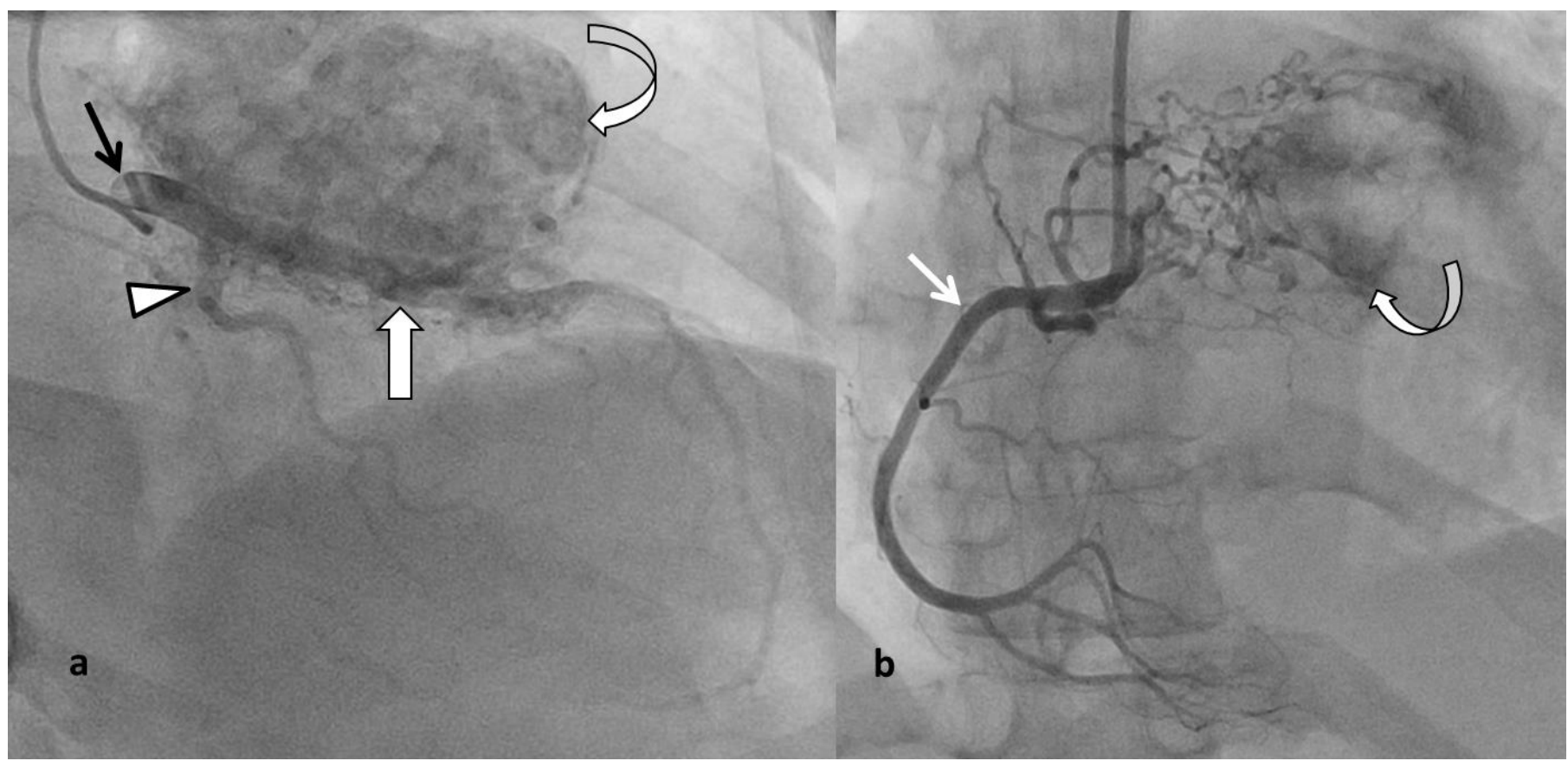

Figure 1: 58-year-old-female with epicardial paraganglioma

FINDINGS: (A) Left coronary angiogram image shows opacification of left main (black arrow), left circumflex (arrowhead) and left anterior descending (black arrow) coronary arteries. Note a vascular epicardial mass (curved arrow) is predominantly supplied by left anterior descending artery. (B) Right coronary angiogram image shows opacification of right coronary artery (white arrow) and multiple feeding vessels from proximal portion supplying the epicardial mass (curved arrow).

TECHNIQUE: Angiography system Philips, AlluraClarity, Netherlands. 


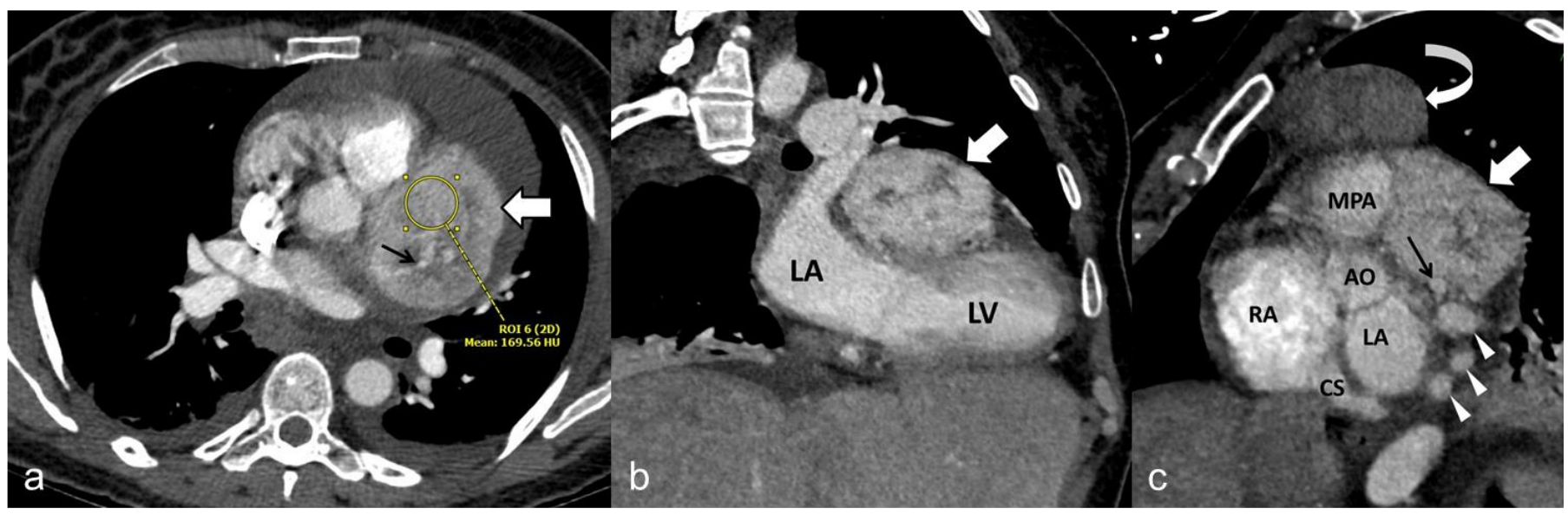

Figure 2: 58-year-old female with epicardial paraganglioma

FINDINGS: (A, B, C) Contrast-enhanced CT (arterial phase) shows a lobulated mass (block arrow) along the anterior superior aspect of the left atrioventricular groove extending cranially up to the level of pulmonary trunk. It shows heterogeneous, rapid, bright enhancement (HU 170) and causes mass effect on underlying left ventricle. Internal dilated arterial branches from left anterior descending coronary artery are present (thin arrow) along with dilated venous channels (arrowheads) draining in coronary sinus. Moderate pericardial effusion and small pleural effusions on both sides are present. The curved arrow points to an anterior mediastinal mass described later.

TECHNIQUE: GE LightSpeed VCT 64 CT scanner, Slice thickness: 1.25 mm; 120 kVp, 500 mAs; Contrast- 85 mL Omnipaque 300 was administered intravenously.
A. Axial soft tissue window, $1.25 \mathrm{~mm}$ slice thickness, Contrast CT
B. Oblique coronal MPR soft tissue window, $1.25 \mathrm{~mm}$ slice thickness, Contrast CT
C. Oblique sagittal MPR soft tissue window, $1.25 \mathrm{~mm}$ slice thickness, Contrast CT

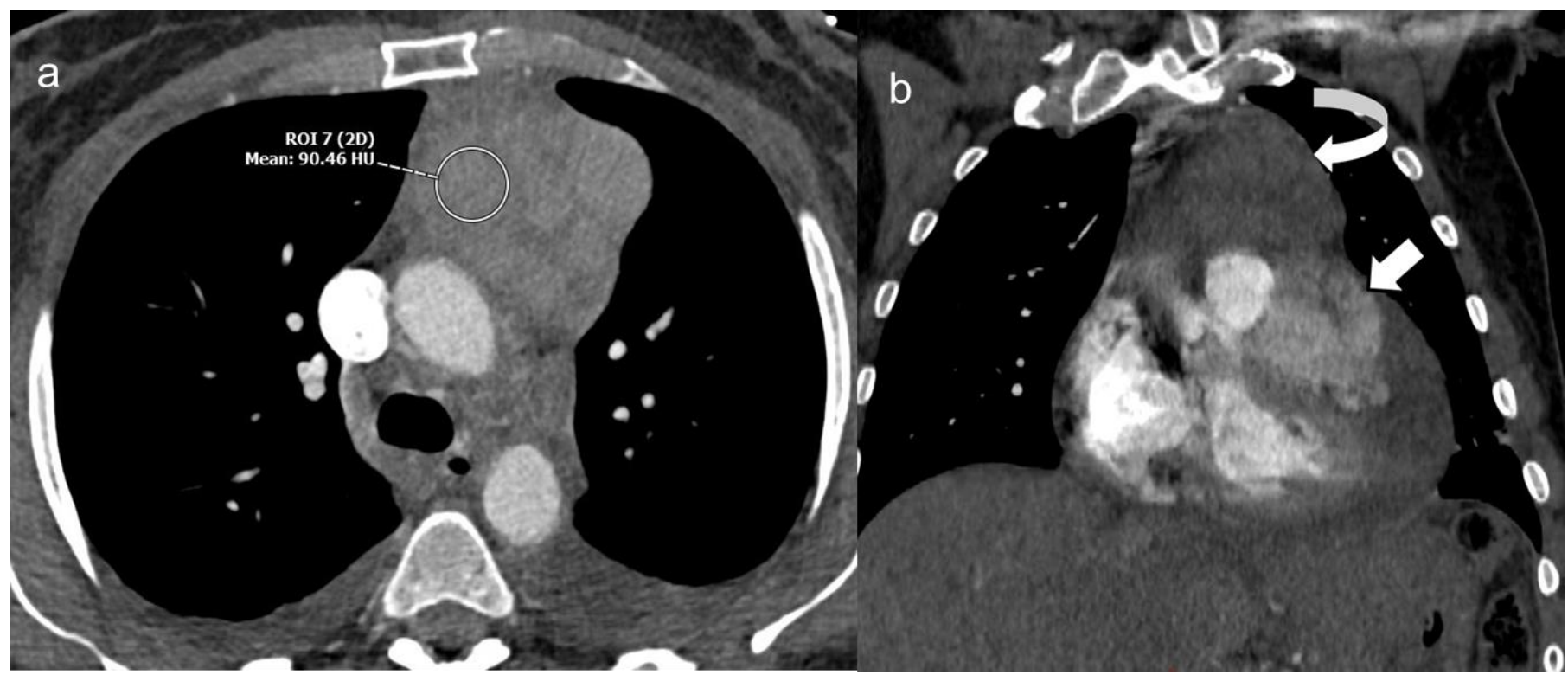

Figure 3: 58-year-old female with anterior mediastinal thymoma

FINDINGS: (A) Contrast enhanced axial CT image (arterial phase) shows a well-defined, lobulated mass in the anterior mediastinum in front of the arch of aorta (curved arrow) with mild homogenous contrast enhancement ( 90 HU). (B) Coronal reformatted contrast CT image shows both masses (block arrow and curved arrow) in close proximity to each other.

TECHNIQUE: GE LightSpeed VCT 64 CT scanner, Slice thickness: 1.25 mm; 120 kVp, 500 mAs; Contrast- 85 mL Omnipaque 300 was administered intravenously.

A. Axial soft tissue window, $1.25 \mathrm{~mm}$ slice thickness, Contrast CT

B. Coronal MPR soft tissue window, $1.25 \mathrm{~mm}$ slice thickness, Contrast CT 
Figure 4 (right): 58-year-old-female with epicardial paraganglioma

FINDINGS: A well defined, heterogeneously echogenic epicardial mass (curved arrow) adjacent to left ventricle (LV) is present with moderate pericardial effusion (block arrow). Note the mass effect on the lateral wall of the left ventricle.

TECHNIQUE: Vivid E95 GE (M5Sc transducer, sector phased, 1.7-3.3 MHz) Horten, Norway.
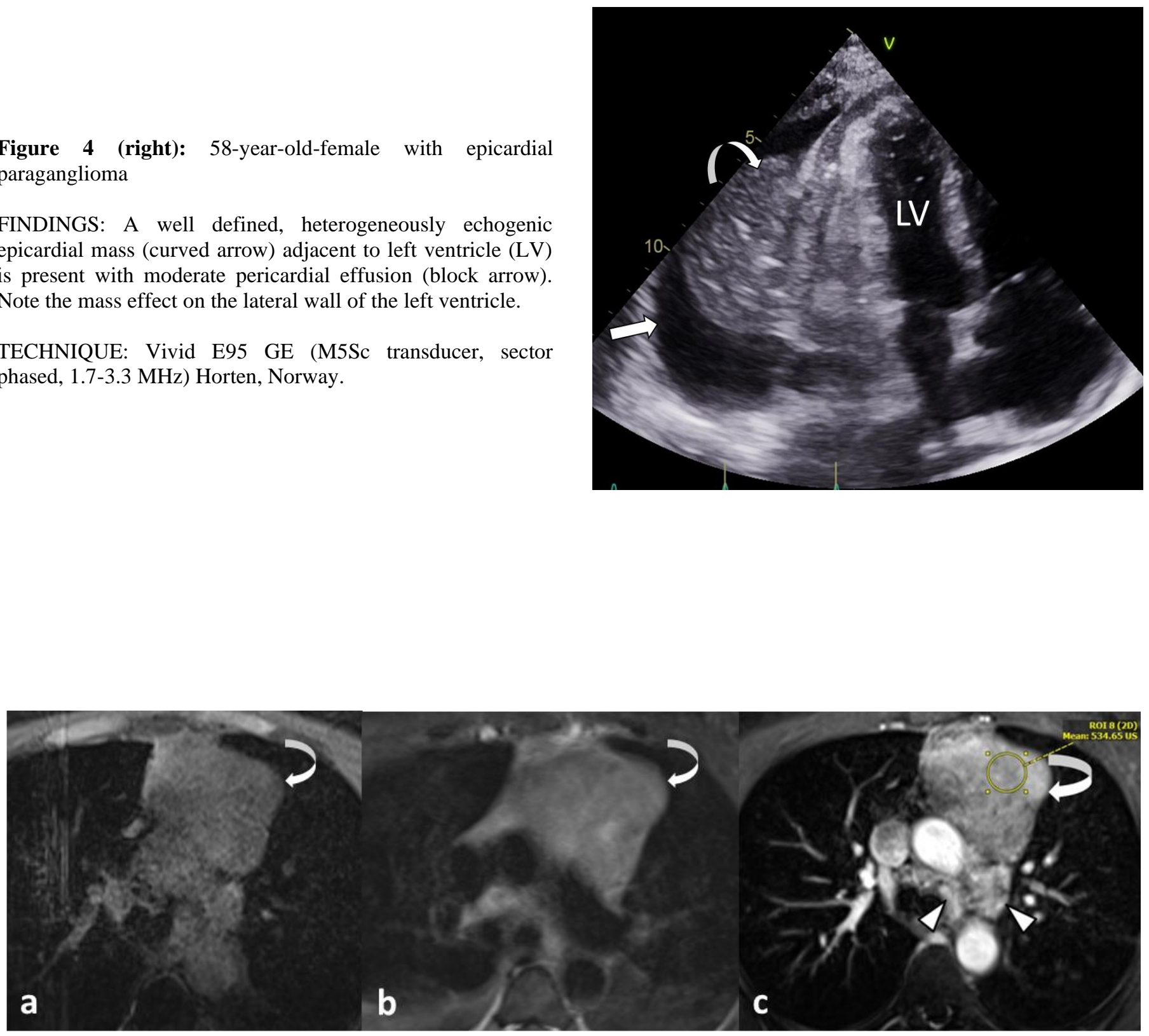

Figure 5: 58-year-old female with anterior mediastinal thymoma

FINDINGS: (A) T1-weighted fat saturated pre contrast image shows iso to low signal intensity (B) T2-weighted fat saturated image shows mildly increased signal intensity of anterior mediastinal mass (curved arrow). (C) Post contrast T1-weighted fat saturated image in arterial phase shows mild homogenous contrast enhancement of the mass. Note mildly enhancing mediastinal lymph nodes in left lower paratracheal and aorto-pulmonary window regions (arrowheads).

TECHNIQUE: Siemens Skyra MR Scanner, magnetic strength 3 Tesla; Intravenous contrast was administered.

A. Axial T1W Pre contrast. TR=3.35ms TE $=1.34 \mathrm{~ms}$. Slice Thickness $3 \mathrm{~mm}$

B. Axial T2W. TR= $3990 \mathrm{~ms}$ TE $=86 \mathrm{~ms}$. Slice Thickness $3 \mathrm{~mm}$

C. Axial T1W Post contrast in arterial phase, $10 \mathrm{~mL}$ Gadavist. TR=3.35ms TE= $1.34 \mathrm{~ms}$. Slice Thickness $3 \mathrm{~mm}$ 


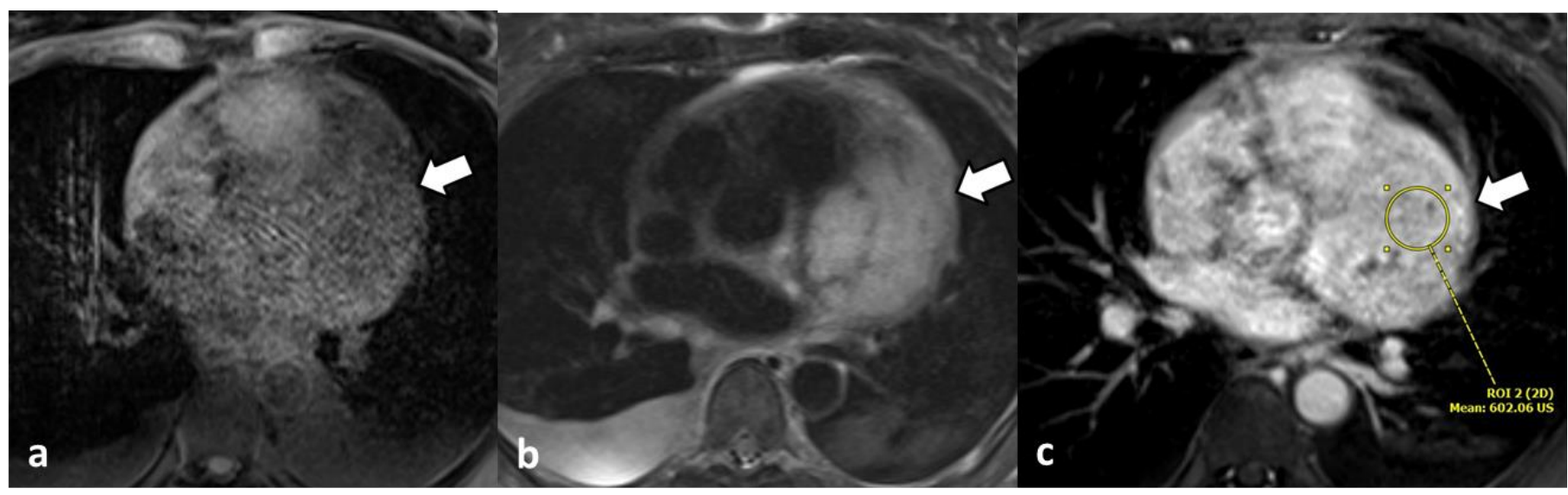

Figure 6: 58-year-old female with epicardial paraganglioma

FINDINGS: (A) T1-weighted fat saturated pre contrast image shows low signal intensity (B) T2-weighted fat saturated image shows markedly high signal intensity of epicardial mass (block arrow). (C) Post contrast T1-weighted fat saturated image in arterial phase shows bright heterogeneous contrast enhancement.

TECHNIQUE: Siemens Skyra MR Scanner, magnetic strength 3 Tesla; Intravenous contrast was administered.

A. Axial T1W Pre contrast. TR=3.35ms TE $=1.34 \mathrm{~ms}$. Slice Thickness $3 \mathrm{~mm}$

B. Axial T2W. TR=3990 ms TE= $86 \mathrm{~ms}$. Slice Thickness $3 \mathrm{~mm}$

C. Axial T1W Post contrast in arterial phase, $10 \mathrm{~mL}$ Gadavist. TR=3.35ms TE= $1.34 \mathrm{~ms}$. Slice Thickness $3 \mathrm{~mm}$

Figure 7 (right): 58-year-old female with epicardial paraganglioma and anterior mediastinal thymoma

FINDINGS: Oblique sagittal MPR images from Post contrast T1-weighted fat saturated sequence shows parietal pericardium (thin arrow) separating the inferiorly located markedly enhancing epicardial mass (block arrow) and the superiorly located, mildly enhancing anterior mediastinal mass (curved arrow). Note the mass effect on the left ventricle and loss of fat plane between the epicardial mass and left ventricle.

TECHNIQUE: Siemens Skyra MR Scanner, magnetic strength 3 Tesla; Intravenous contrast was administered.

MPR T1W Post contrast in arterial phase, $10 \mathrm{~mL}$ Gadavist. $\mathrm{TR}=3.35 \mathrm{~ms} \mathrm{TE}=1.34 \mathrm{~ms}$. Slice Thickness $2.7 \mathrm{~mm}$

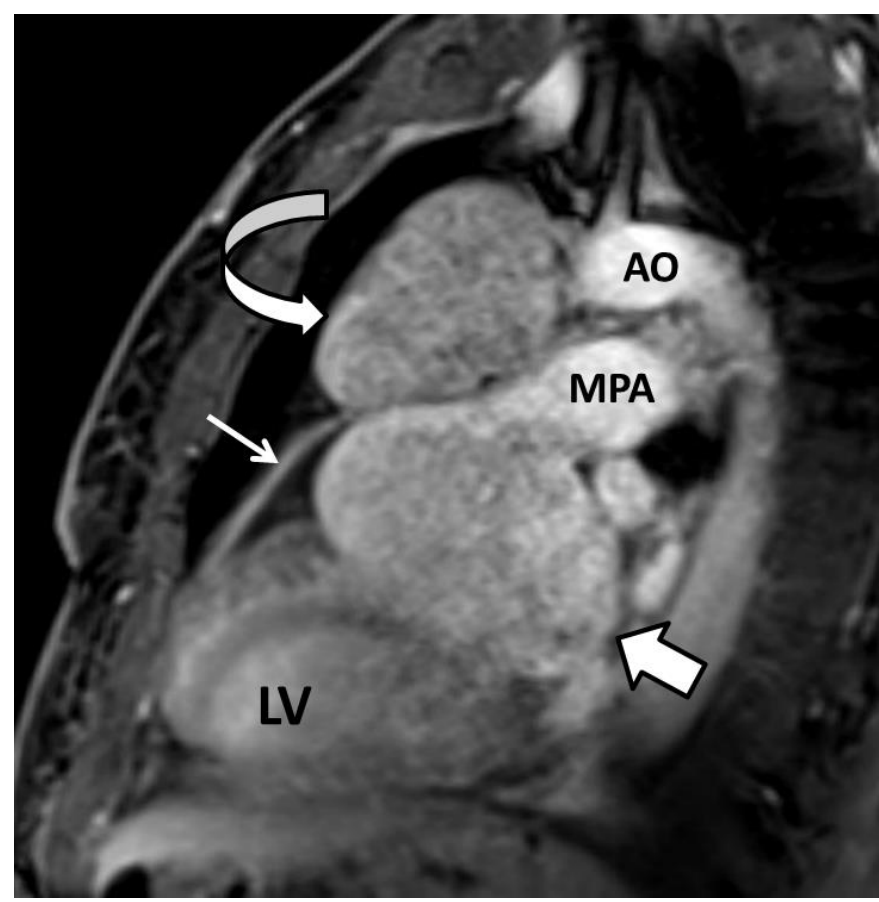



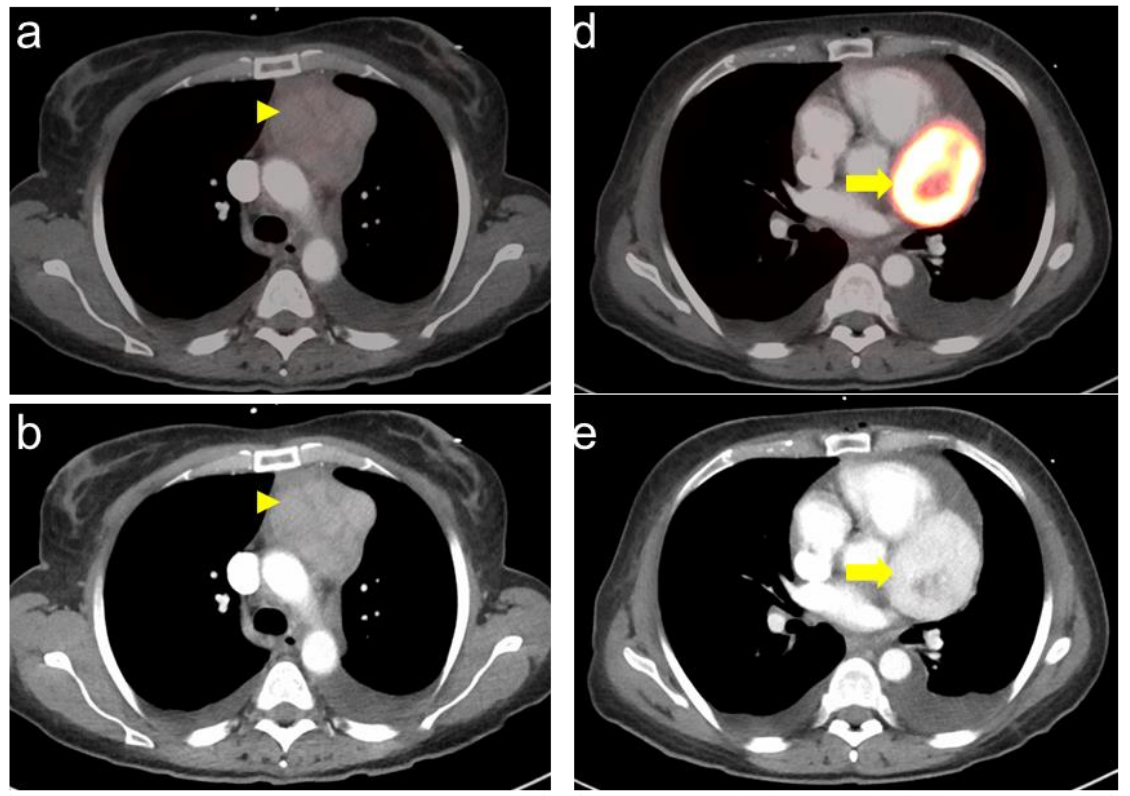

\section{g}

C

f

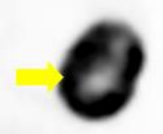

Figure 8: 58-year-old female with epicardial paraganglioma and anterior mediastinal thymoma

FINDINGS: (A, B, C, D, E, F) Selected images from the DOTA-TATE PET and concurrent contrast enhanced CT examinations. Trans axial fused DOTA-TATE PET/CT (a) contrast enhanced CT (b) and DOTA-TATE PET (c) images show an anterior mediastinal mass with only mild DOTA-TATE uptake with a maximum SUV of 2.9 (yellow arrowhead). Trans axial fused DOTA-TATE PET/CT (d) contrast enhanced CT (e) and DOTA-TATE PET (f) images show an left epicardial mass with a maximum SUV of 68.7 (yellow arrow). Coronal DOTA-TATE PET maximum intensity projection (MIP; g) demonstrates uptake within the known lesions and no other foci of increased DOTA-TATE uptake to suggest metastatic somatostatin avid disease.

TECHNIQUE: General Electric Discovery MI PET/CT, Slice thickness: 3.75 mm; 140 kVp, 1-12 mAs, 500 ms Exposure Time. Intravenous gallium Ga-68 dotatate injection (Ga-68 NETSPOT), 5.4 millicurie administered, 51 minutes of circulation time before imaging acquisition.

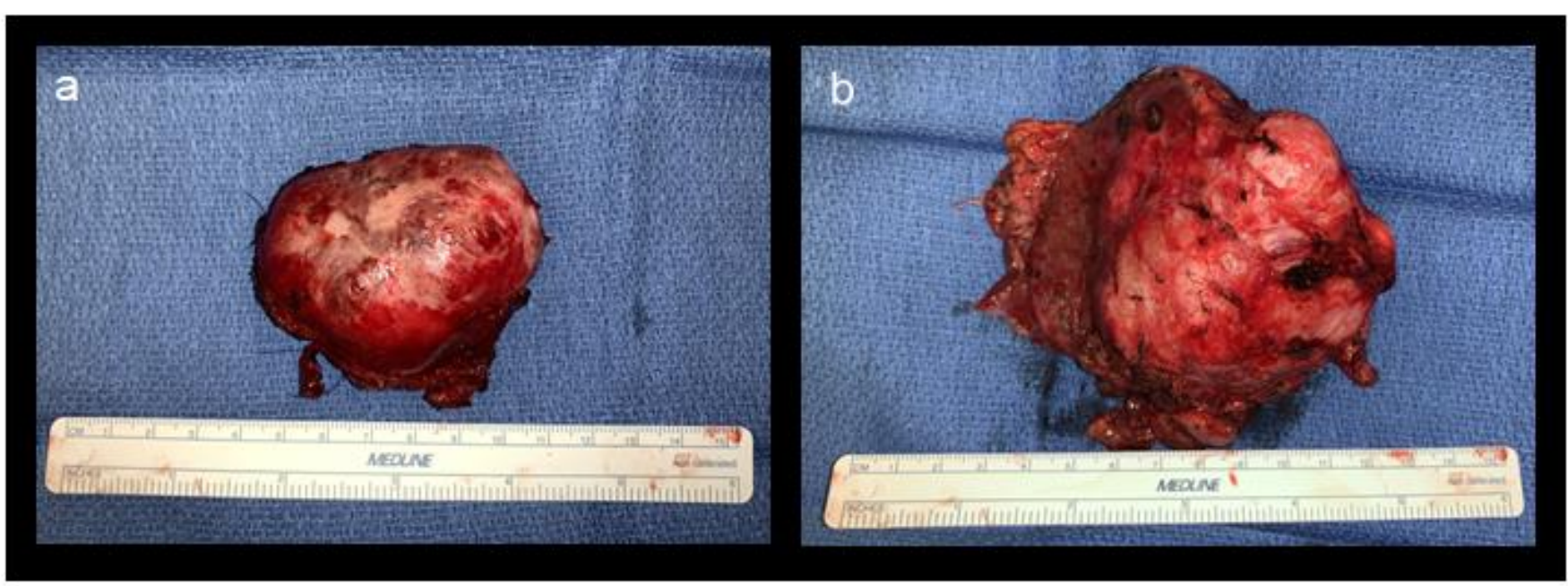

Figure 9: 58-year-old female with epicardial paraganglioma and anterior mediastinal thymoma

Gross surgical specimens showing the $6.5 \mathrm{~cm}$ epicardial mass, pathologically proven paraganglioma (a) and $9 \mathrm{~cm}$ anterior mediastinal mass, pathologically proven thymoma (b). 


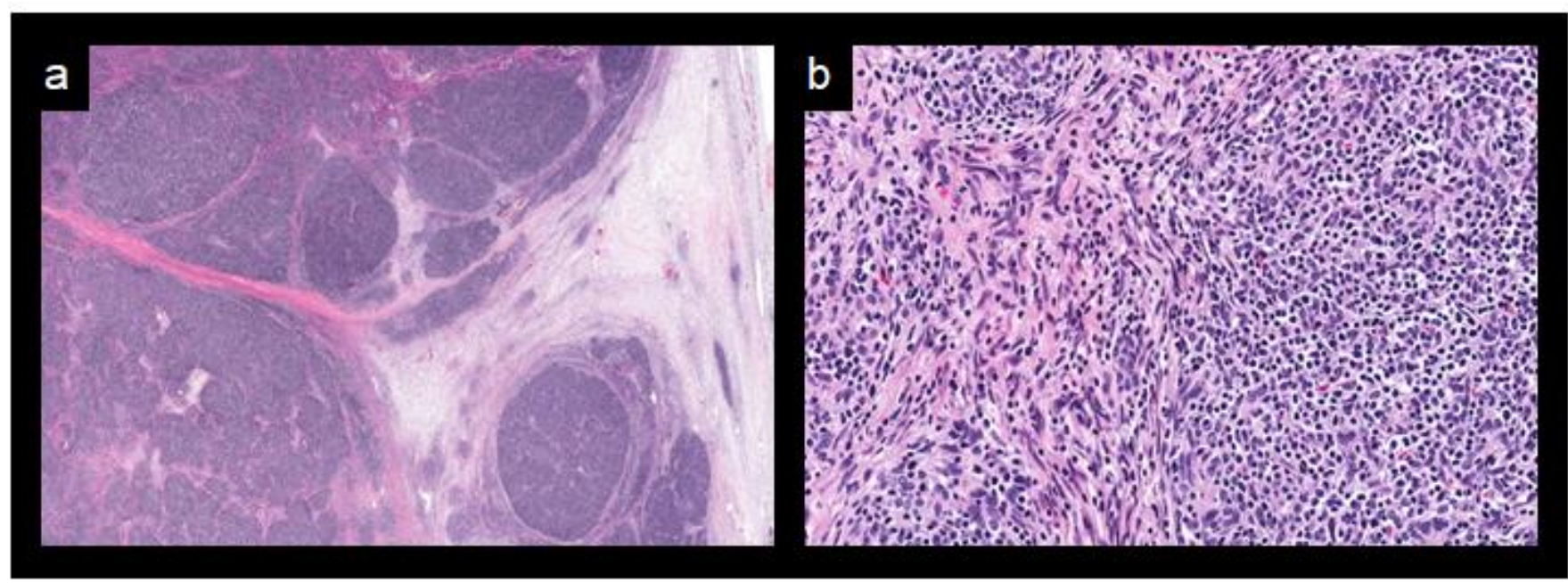

Figure 10: 58-year-old female with anterior mediastinal thymoma

Histologically, the anterior mediastinal mass was well demarcated and showed a lobulated architecture (a). At higher magnification, it exhibited characteristic features of a type AB thymoma with both lymphocyte-poor type A and lymphocyte-rich type B elements (b).

Technique: Histopathology. Stain: Hematoxylin and Eosin; Original Magnification: (a) 8X (b) 200X

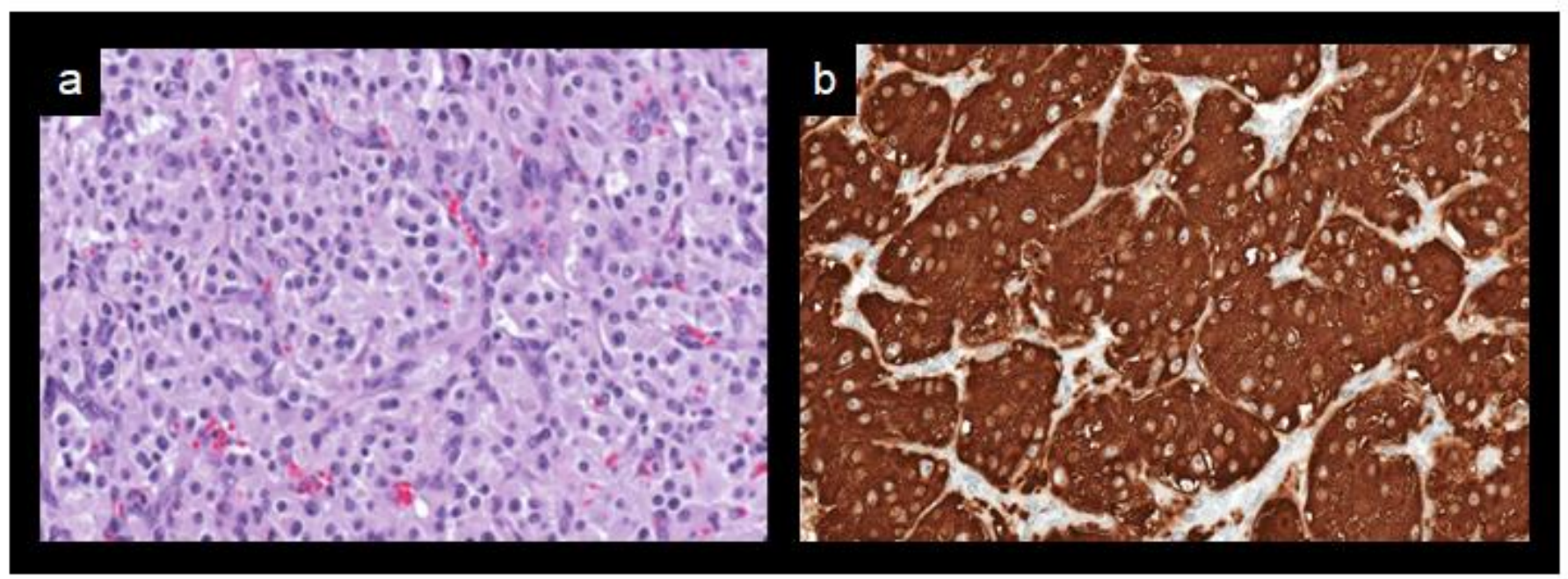

Figure 11: 58-year-old female with epicardial paraganglioma

The bland, round or oval synaptophysin-positive tumor cells were arranged in small well-formed nests (Zellballen) (a), which stained positive for synaptophysin (b). These findings are typical for paraganglioma.

Technique: Histopathology. Stain: (a) Hematoxylin and Eosin, (b) Synaptophysin; Original Magnification: (a) 400X (b) 400X 


\begin{tabular}{|l|l|}
\hline Etiology & Majority sporadic with approximately one third hereditary. \\
\hline Incidence & $\begin{array}{l}\text { Approximately 0.8 per 100,000 person years with around 500 to } 1600 \text { cases annually in the United } \\
\text { States }\end{array}$ \\
\hline Gender Ratio & $\begin{array}{l}\text { Sporadic cases are seen much more commonly in women. Hereditary cases are distributed equally } \\
\text { between men and women }\end{array}$ \\
\hline Age Predilection & Most commonly between 30 to 50 years of age. \\
\hline Risk Factors & $\begin{array}{l}\text { Most paragangliomas are sporadic. Hereditary paragangliomas make up one third to one half of } \\
\text { diagnosed paragangliomas and are often associated with a genetic abnormality. }\end{array}$ \\
\hline Treatment \& Prognosis & $\begin{array}{l}\text { For paragangliomas without local spread /invasion, surgical excision remains the standard of care. } \\
\text { The majority of paragangliomas are benign with approximately 15-35\% displaying malignant } \\
\text { behavior. }\end{array}$ \\
\hline Findings on Imaging & $\begin{array}{l}\text { CT: homogenous, soft tissue masses that strongly enhance with intravenous contrast. } \\
\text { MRI: a soft tissue mass with relatively high T1 signal intensity, flow voids may be present due to } \\
\text { dilated vessels. They show marked T2 high signal intensity compared to liver on T2 weighted } \\
\text { images ('light bulb sign') and marked enhancement with gadolinium [Ga-68] DOTA-TATE and [I- } \\
\text { 123] metaiodobenzylguanidine (MIBG): radiotracer accumulation at the site of primary } \\
\text { paraganglioma and any metastatic foci with high specificity and sensitivity. }\end{array}$ \\
\hline
\end{tabular}

Table 1: Summary table for paraganglioma.

\begin{tabular}{|l|l|}
\hline Etiology & Most sporadic with rare cases of hereditary syndrome associated. \\
\hline Incidence & Approximately 0.13 cases per 100,000 person years. \\
\hline Gender Ratio & Equal predilection between men and women. \\
\hline Age Predilection & Most commonly between 40 to 60 years of age. \\
\hline Risk Factors & Age and ethnicity. \\
\hline Treatment \& Prognosis & Thymectomy remains the standard of care. Prognosis varies widely based on histologic grade. \\
\hline Findings on Imaging & $\begin{array}{l}\text { CT: rounded or lobulated, homogenous, soft tissue mass in the anterior mediastinum anywhere } \\
\text { from suprasternal notch up to the diaphragm. } \\
\text { MRI: iso-low T1, intermediate T2 signal intensity with variable, typically mild, contrast }\end{array}$ \\
$\begin{array}{l}\text { enhancement. Areas of cavitation or calcifications are rare in low grade thymoma. } \\
{[\text { F-18] 2-fluoro 2-deoxy-D glucose (FDG) PET-CT: helps to distinguish between low risk thymoma }} \\
\text { and high risk thymoma/thymic carcinomas }\end{array}$ \\
\hline
\end{tabular}

Table 2: Summary table for thymoma. 


\begin{tabular}{|c|c|c|c|}
\hline $\begin{array}{l}\text { Differential } \\
\text { Diagnosis }\end{array}$ & CT & MRI & Enhancement \\
\hline Metastasis & \multicolumn{3}{|c|}{$\begin{array}{l}\text { Varied imaging appearance and degree of contrast enhancement based on primary } \\
\text { malignancy. Pericardial location more common than epicardial or myocardial. Accompanying pericardial } \\
\text { effusion and/or thickening is often present. }\end{array}$} \\
\hline $\begin{array}{l}\text { Primary } \\
\text { pericardial } \\
\text { malignancy }\end{array}$ & $\begin{array}{l}\text { Varied appearance. Often shows } \\
\text { loco/regional invasion. }\end{array}$ & $\begin{array}{l}\text { Marked internal heterogeneity, and } \\
\text { restricted diffusion. }\end{array}$ & Variable contrast enhancement. \\
\hline $\begin{array}{l}\text { Venolymphatic } \\
\text { malformation- } \\
\text { Hemangioma }\end{array}$ & $\begin{array}{l}\text { Lobulated fluid/soft tissue } \\
\text { attenuation lesion with adjacent } \\
\text { and internal vascularity, } \\
\text { Calcifications may be present. }\end{array}$ & $\begin{array}{l}\text { Intermediate T1-weighted signal } \\
\text { intensity and high T2-weighted } \\
\text { signal intensity compared to } \\
\text { muscle. }\end{array}$ & $\begin{array}{l}\text { Rapid contrast enhancement in } \\
\text { smaller lesions and } \\
\text { rapid/progressive filling in } \\
\text { larger lesions. }\end{array}$ \\
\hline $\begin{array}{l}\text { Venolymphatic } \\
\text { malformation- } \\
\text { Lymphangioma }\end{array}$ & $\begin{array}{l}\text { Lobulated or infiltrative fluid } \\
\text { attenuation lesion, typically } \\
\text { multiseptated }\end{array}$ & $\begin{array}{l}\text { Low T1-weighted signal intensity, } \\
\text { high T2-weighted signal intensity } \\
\text { with dark internal septations }\end{array}$ & $\begin{array}{l}\text { Multicystic lesion with mild } \\
\text { enhancement of internal septa. } \\
\text { Sometimes appears as solid } \\
\text { lesion due to enhancement of } \\
\text { densely packed septa within. }\end{array}$ \\
\hline $\begin{array}{l}\text { Coronary artery } \\
\text { malformation- } \\
\text { Aneurysm, } \\
\text { Arterio-venous } \\
\text { malformation }\end{array}$ & \multicolumn{3}{|c|}{$\begin{array}{l}\text { Aneurysm is focal vascular dilation whereas arterio-venous malformation is seen as lobulated lesion with } \\
\text { entangled, dilated vascular channels showing dilation of draining vein more than the feeding arteries. } \\
\text { While imaging appearances can be varied, the malformation shows direct communication with one or more } \\
\text { coronary vessels. MRI signal follows fluid/blood signal intensity and shows vascular pattern of contrast } \\
\text { enhancement. }\end{array}$} \\
\hline $\begin{array}{l}\text { Ectopic thyroid } \\
\text { and parathyroid } \\
\text { tissue }\end{array}$ & $\begin{array}{l}\text { Well-defined soft tissue density } \\
\text { nodule }\end{array}$ & $\begin{array}{l}\mathrm{T} 1 \text { isointensity to mildly } \\
\text { hyperintensity and } \mathrm{T} 2 \text { mild } \\
\text { hyperintensity compared to } \\
\text { muscle. }\end{array}$ & $\begin{array}{l}\text { Good contrast enhancement } \\
\text { (parathyroid) can help identify } \\
\text { the tissue of origin. Of note, } \\
\text { nuclear medicine studies with } \\
\text { [I-123/I-131] radioiodine } \\
\text { (thyroid) and [Tc-99m] } \\
\text { sestamibi (parathyroid) can } \\
\text { help identify tissue of origin. }\end{array}$ \\
\hline
\end{tabular}

Table 3: Differential diagnosis table for paraganglioma.

\begin{tabular}{|c|c|c|c|}
\hline Differential Diagnosis & CT & MRI & Enhancement \\
\hline Lymphadenopathy & \multicolumn{3}{|c|}{$\begin{array}{l}\text { Mildly enhancing, often lobulated soft tissue mass. Variable, typically iso-low signal intensity on T1 } \\
\text { and T2-weighted images. Multifocal involvement favors lymphadenopathy over thymoma. }\end{array}$} \\
\hline $\begin{array}{l}\text { Retrosternal extension } \\
\text { of thyroid mass }\end{array}$ & \multicolumn{3}{|c|}{$\begin{array}{l}\text { Thyroid goiter or malignancy can lead to gland enlargement and mediastinal extension. Variable } \\
\text { signal intensity and degree of contrast enhancement. Anatomical continuity with the thyroid gland is } \\
\text { seen. }\end{array}$} \\
\hline $\begin{array}{l}\text { Germ cell tumor } \\
\text { (i.e. Teratoma) }\end{array}$ & \multicolumn{3}{|c|}{$\begin{array}{l}\text { Heterogeneous mass with solid and cystic components with or without calcifications. } \\
\text { The presence of macroscopic fat is nearly pathognomonic for teratomas. }\end{array}$} \\
\hline
\end{tabular}

Table 4: Differential diagnosis table for thymoma. 


\section{ABBREVIATIONS}

$\mathrm{CT}=$ Computed Tomography

CTA $=$ Computed Tomography Angiogram

DOTA-TATE $=[68 \mathrm{Ga}]-$ DOTA-(Tyr3)-octreotate

FDG = Fluorine-18 2-fluoro 2-deoxy-D glucose

Max SUV = Maximum standardized uptake value

MEN = Multiple endocrine neoplasia

MIBG $=$ [123I $]$-metaiodobenzylguanidine

MRI = Magnetic Resonance Imaging

PET-CT $=$ Positron Emission Tomography-Computed

Tomography

PGL $=$ Paraganglioma syndrome

PGL4 = Paraganglioma Syndrome 4

$\mathrm{SDH}=$ Succinate dehydrogenase complex

SDHB = Succinate dehydrogenase complex iron sulfur subunit

B

SI = Signal intensity

\section{KEYWORDS}

Cardiac; Epicardial; Paraganglioma; Mediastinal Mass; Thymoma; Hereditary; CT; MRI; Gallium-68 DOTA-TATE; PET-CT; Succinate dehydrogenase (SDH) subunits

\section{Online access}

This publication is online available at:

www.radiologycases.com/index.php/radiologycases/article/view/4101

\section{Peer discussion}

Discuss this manuscript in our protected discussion forum at: www.radiolopolis.com/forums/JRCR

\section{Interactivity}

This publication is available as an interactive article with scroll, window/level, magnify and more features.

Available online at www.RadiologyCases.com

\section{Published by EduRad}

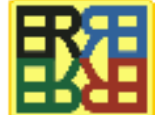

www.EduRad.org 